\title{
Improving relationship quality between main contractors and sub-contractors in Indonesian Infrastructure Projects
}

\author{
Yosi Agustiawan ${ }^{1 *}$, Vaughan Coffey $^{2}$, and Fiona Lamari ${ }^{2}$ \\ ${ }^{1}$ Universitas Pesantren Tinggi Darul Ulum (Unipdu), Indonesia \\ ${ }^{2}$ Queensland University of Technology (QUT), Australia
}

\begin{abstract}
This paper has two main sections, the first of which provides a summarized review of the literature focusing on existing studies of the adversarial relationships between main and sub-contractors in project execution phases. Such relationships become hurdles for the construction organizations to achieve quality relationships. Organizational culture influences these relationships due to its constituent elements of value, leadership style, procedures, and routine, as well as defining success or failure. Drawing from the first section, the second section presents the details of the research project being undertaken. Suitable research methods have been developed to meet the research objectives eliciting based on fundamental questions. Primary data collection will use a mixed methods approach, i.e., questionnaire surveys and semi-structured interviews to obtain respondents opinions related to social interactions in Indonesian infrastructure projects. The project-based organizational culture assessment of Zou (2014) and relationship quality evaluation of Jiang (2016) are utilized in this study. Statistical software will be used to analyze most data expected to be obtained in the future and then the results will be discussed to develop a framework to improve relationship quality in achieving project performance.
\end{abstract}

\section{Introduction}

In recent years, almost every nation globally is striving to enhance its competitiveness by investing huge resources in large-scale infrastructure programmes and projects. According to an Oxford Economics research study [1], the global expenditure on infrastructure is predicted to reach approximately USD 9 trillion per year by 2025. In Indonesia, Databooks [2] reported that the government's infrastructure spending had increased steeply from about USD 6 billion in 2009 to around USD 29 billion in 2017, almost a five-fold increase.

Although the rollout of such a scale of infrastructure development is very promising, generally only larger companies have the opportunity to bid as main contractors, due to the fact that these projects require them to cover high investment costs when undertaking the work. Since most sub-contractors are categorized as small and medium-sized enterprises

*Corresponding author: yosiagustiawan@fft.unipdu.ac.id 
(SMEs) [3], their involvement in such infrastructure developments depends upon them working under the mantle of a larger building, or general engineering, contractor companies (i.e., upper-tier contractors) [4]. In the UK construction industry, some sub-contractors had sustained their existence within the industry for nearly 20 years due to maintaining good relationships with the larger general contractors [5].

General contractors usually employ a variety of sub-contractors, either sourced locally, or occasionally drawn from overseas, to accomplish specialized works such as plumbing, electrical, or other types of trade contracts for which they (the main contractors) do not have specific expertise to undertake [4]. Although this enables the general contractors to share their project risks, it also escalates the complexity of project organizations, thus amplifying the possibility, under certain circumstances, of increasing tension between the parties undertaking projects. This negative effect of this adversarial atmosphere causes increasingly severe problems [6]. In 2016, the Australian Bureau of Statistics [7] revealed that $43 \%$ of conflicts (workplace conditions, health and safety, job security, and managerial policy) occur in the construction industry, which places the industry as the sector with the highest number of industrial disputes. This alarming figure raises an urgent need for both large contracting firms and small sub-contractors to come together and ensure that they collaborate for mutual benefit. Otherwise, the main project goals, such as project delivery time, cost and quality, will all suffer [8].

\section{Literature review}

\subsection{Relationship management in construction industry}

The development of a project management paradigm, moving from the traditional approach to a more relationship-based approach, has been growing over the past two decades. The former approach is based on formal tools and techniques and places emphasis on control mechanisms to achieve efficiency. Meanwhile, the relationship-based approach focuses on effectiveness [5] and refer to social and dynamic interaction processes between project parties [9].

The relationship-based approach is complementary to other approaches for managing projects. Although this method has often proved to be more successful than traditional methods [10], many projects today still use traditional project management methods such as competitive tendering and the letting of conventional forms of the contract between main and sub-contractors. However, in some cases, traditional methods still have the same positive effects on project performance as the alternative relationship-based approach [5]. For example, an empirical study conducted by Doloi [11] demonstrated that in both traditional and relational contracting, project success was directed by cost efficiency, trust, and communication. According to Bygballe, Swärd, and Vaagaasar [8], in project partnering, the traditional contract form remained important as a tool for coordinating, resolving conflicts and creating job descriptions among partners.

Much of the extant project management literature has a considerable focus on investigating the implementation of the relationship-based management method in an upstream (client/ main contractors) context. The literature reveals that relationship management has significantly contributed to the performance of projects in the areas of resolving disputes quickly and efficiently [11], improving the teamwork approach, reducing cost and confrontation [6], harmonizing the project community [12], and sustainable supply chain management [13].

Meanwhile, less attention has been placed on relationship management studies in the downstream supply chain. As a consequence Smyth [5] revealed that research study into 
downstream relationship management is relatively underdeveloped, or largely being ignored. However, in a few studies, the relationship-management method has also demonstrated positive results regarding the establishment of collaborative teamwork between main and sub-contractors. For instance, a longitudinal study conducted by Wood and Ellis [14] revealed that both primary and sub-contractors reported that they had positive perceptions and experiences during partnering. As a result, after examining factors that influenced sub-contractor/ general contractor relationships from the sub-contractors' perspective, and McCord and Gunderson [4] concluded that better relationships could help to ensure future work.

\subsection{Assessing the quality of relationship in projects}

Jiang et al. [15] indicated that there had been many ways to assess relationship quality grounded in the former marketing studies. However similar evaluation of relationship quality both formal and informal in a construction project context is still only rudimentary [16]. For example, a comprehensive literature study conducted by Bygballe, Jahre, and Swärd [9] revealed that relationship duration and development, and relationship partners, dominated the discussion of relationships in the construction industry. On the other hand, even though the dimensions influencing relationship quality, and regarding the effect of those dimensions on relationships in the construction sector were mentioned by several authors, see $[13,17,19]$ none of these authors have proposed how to specifically measure relationship quality.

Jiang [15] literature review on relationship quality measurement in marketing studies found similar dimensions with the construction studies. Furthermore, the author [15] proposed a measurement model of relationship quality, namely CLOSES. This multidimensional scale of relationship quality reflects the intensity of communication (C), long-term orientation (LO), and social and economic satisfaction (SES) of a key role in a business relationship. The CLOSES included long-term orientation, whereas in contrast excluded trust and commitment. The former reason is that this construct has been proven as the key feature of relationship quality from previous studies [19]. Meanwhile, excluding trust and commitment is intended to avoid tautological error since these two dimensions are considered as an antecedent in most studies of relationship quality [15].

CLOSES has addressed measurement issues of relationship quality from previous studies [15]. The means for quantifying relationship quality developed by some authors were valid only on specific industry setting [20]. For example, the ways the scale examined relationships between service firms and their customer [21], between manufacture and distributors [22], and between salesperson and customer [23]. Since CLOSES has been tested in various industries, this scale can be used as a reliable tool to assess business to business relationships for all industry sectors [15].

\subsection{Organizational culture related to relationship quality}

Adopting and implementing relationship management in a large system requires the two parties of a relationship to adopt similarly, or absorb each other's, organizational culture. Bresnen and Marshall [24] noted organizational culture might prevent or support a relational approach. Accordingly, successful implementation of a strategic partnership, alliance, cooperation requires culture changes [25]. A process will effectively operate if the combination of formal and informal procedures arranged by management align with norms of the organization, otherwise, they emerge as disruptive factors [26].

The development of an appropriate culture of relationships is key to an effective culture change and can support a relationship approach. Therefore, project parties should be 
encouraged to change their behaviors and/ or attitudes [24] to put in place relationship quality as a common interest [27] in an effort to harmonize the working environment, see $[13,28,29]$. A change in attitude is required to attain an understanding of the importance of relationship quality at all levels of an organization: thus, it allows individuals to become role models for others [30]. In this way, key personnel must facilitate the transformation through changing mindsets and the actions of processes, strategies, and beliefs of an organization [31]. Also, adopting new systems and methods must be undertaken along with changing underlying assumptions and values, hence altering organizational culture [33].

\subsection{Project-based organizational culture models}

Investigating project-based organizational culture by employing a well-known organizational culture model and its original instrument is a standard method [34]. However, assessing culture in temporary multi-organisations as the nature of construction projects by utilizing a well-recognized organizational culture model has some limitations because the model is often unable to cover the specific characteristics of project basedorganizations [33]. In order to accommodate those specific characteristics when assessing project-based organizational culture, Zou [35] proposed a framework based on the modification of well-established organizational culture models, see $[36,37]$. The framework was developed through a comprehensive study.

Zuo study [34] criticized previous studies related to the use of organizational culture models in construction projects. For example, He argued that that the approach used from the study of Andersen [38] as well as Thomas, Marosszeky, Karim, Davis, and McGeorge [39] is too simple since their studies only select one available instrument of a wellestablished organizational culture model and then delivers the instrument to respondents. Both Andersen [38] and Thomas et al. [39] overridden project based-organizations' characteristics [40] and the influence of each national and organizational culture of the project parties [41].

Also, Zuo [34] contended that the model recommended by Kumaraswamy [42] is too complicated to implement. Kumaraswamy model [42] was derived from a set of four overlapping sub-cultures (organizational sub-culture, operational sub-culture, professional sub-culture, and individualistic sub-culture). Since the model suggested that each subculture must be assessed by applying Hofstede's cultural model [37] and there are many organizations as well as professionals involved in a particular project, it understands that analyzing project-based organizational culture necessarily requires a large number of resources.

Accordingly, by using a similar procedure with Dharmayanti's study [43] like combining and modifying well-established organizational culture models, Zuo [33] proposed a framework to investigate organizational culture in projects. The author [33] adapted existing instruments from the work of Cameron and Quinn [36] and Hofstede [37] to suit with construction projects context. One of the main reasons is an element of integration between the functional departments of one organization, which is stressed by existing models, should be adapted to the integration of numerous services in construction projects.

\section{Methodology}

Emanating from the explanations in the previous section, and with regard to the potential influence of organizational culture on relationship quality, it appears to be essential to investigate how relationship management is implemented in the downstream project 
execution phase, with a particular emphasis on the role of relationship quality and organizational culture in achieving successful project performance and outcomes.

This current research combines two types of research questions 'what' and 'how'. Fellows \& Liu [44] suggested that mixing both quantitative and qualitative approaches is a suitable approach to address those questions. Hence, this current study will conduct a questionnaire survey (quantitative approach), while semi-structured interviews will be organized as a part of a qualitative approach, i.e., it will adopt a 'mixed methodology' overall approach.

The questionnaire survey is quantitative due to using a numerical itemized rating scale [44]. Its purpose is to collect factual evidence about the existing practices and levels of relationship management and identify any connection between relationship management and organizational culture, in the Indonesian context. Following the survey, this study will handle interviews with several construction practitioners. Interviewing not only allows the researcher puts behavior in context, but it also enables the researcher conceives reasoning and understanding from the respondent's perspective [45]. More importantly, an interview is aimed to grasp the lived experience of other people being interviewed [46].

\subsection{Content of questionnaire}

The construct of RQ indicates that the interplay of four elements (communication, economic satisfaction, social satisfaction, and long-term orientation) was an appropriate approach to assessing RQ. The use of four elements when evaluating the relationships is justified as previous research has revealed that those four dimensions are closely associated and/ or correlated with RQ [15]. Furthermore, Jiang [15] proposed the CLOSES model to assess RQ that can be used in all industries sector. The theory used in developing this model has adapted the work of several authors who have researched RQ in the marketing sector.

The project-based organizational culture construct was adopted from the model developed by Zuo [35]. Based on the literature review, both comprehensive studies conducted by Dharmayanti [43] and Zuo [34] combined and modified well-established organizational culture models when investigating a specific organization. It can be concluded by adapting existing organizational culture models in their studies can provide satisfactory results.

\subsection{Semi-structure interview}

Interviewing provides qualitative researchers approach the context and reasons of people's actions, and a technique to conceive the meaning contributors do those actions [46]. Drawing from Witzel and Reiter [47], Qoyyimah [45] explained that the two types of interviews had been widely used in qualitative researches, namely the miner-interviewer and the traveler-interviewer. However, the two types have a weakness: for instance, the former is unable to accommodate the change of assessment criteria while the latter is likely to encounter many impressions and perspectives.

Accordingly, Witzel and Reiter [47] proposed a well-informed traveler as another interviewing. This type stresses that well-informed interviewers should have "certain priorities and expectations and start with the journey by background information obtained beforehand [49]". This type also constructs the problem-center interview (PCI) which places the research problem in the center of the interview. Since PCI focuses on making meaning around facets related to the problem, a semi-structured interview frame will be used to avoid respondents speaking off topic. 


\subsection{Data collection}

Under the case study umbrella, this research selected three Indonesian transport infrastructure projects (i.e. toll-road 1, toll-road 2, and railway project) based on the data provided by Databoks [48]. There were 10 participants from the client, contractor, consultant, supplier/subcontractor's organisations agreed to join in the interviews. Meanwhile, the questionnaire was directly hand-delivered to 10 respondents of Case 1,10 respondents of Case 2, and 10 respondents to Case 3. After two weeks, this research collected the responses, and there were, in total, 25 responses collected.

\section{Results and discussion}

As all the significance values (see Table 1) is less than 0.05 excepts 'flexible and peopleoriented', it can be concluded that there is a significant difference in the PBO-culture of the projects (except flexible and people-oriented) across the three selected projects. In other words, this test indicates that there are different types of PBO-culture in the Indonesian transport infrastructure projects.

Table 1. Kruskal-Wallis test between the PBO-culture and type of the projects

\begin{tabular}{|l|c|c|}
\hline & Chi-Square & Asymptotic significance \\
\hline Integrative & 17.383 & .000 \\
\hline Cooperative & 18.384 & .000 \\
\hline Goal-oriented & 8.992 & .011 \\
\hline Flexible & 6.873 & .032 \\
\hline People-oriented & 10.693 & .005 \\
\hline
\end{tabular}

The mean rank is used to understand the characteristic of the three selected projects. Table 2 shows that in general, the PBO-culture of toll-road 2 projects were characterised as more integrative, cooperative, goal-oriented, flexible and people-oriented than the two other projects.

Table 2. Mean rank values of each dimension of the PBO-culture across three various projects

\begin{tabular}{|l|c|c|c|}
\hline & Toll-road 1 & Toll-road 2 & Railway \\
\hline Integrative & 16.40 & 23.20 & 6.90 \\
\hline Cooperative & 12.50 & 20.00 & 5.00 \\
\hline Goal-oriented & 8.40 & 12.00 & 3.60 \\
\hline Flexible & 10.00 & 13.25 & 5.25 \\
\hline People-oriented & 10.50 & 13.92 & 4.08 \\
\hline
\end{tabular}


A radar chart of mean values (see Fig. 1) illustrates that there were different levels of relationship in the three selected projects. Clearly, the relationship quality between parties in the toll-road 2 project was better than the other two projects.

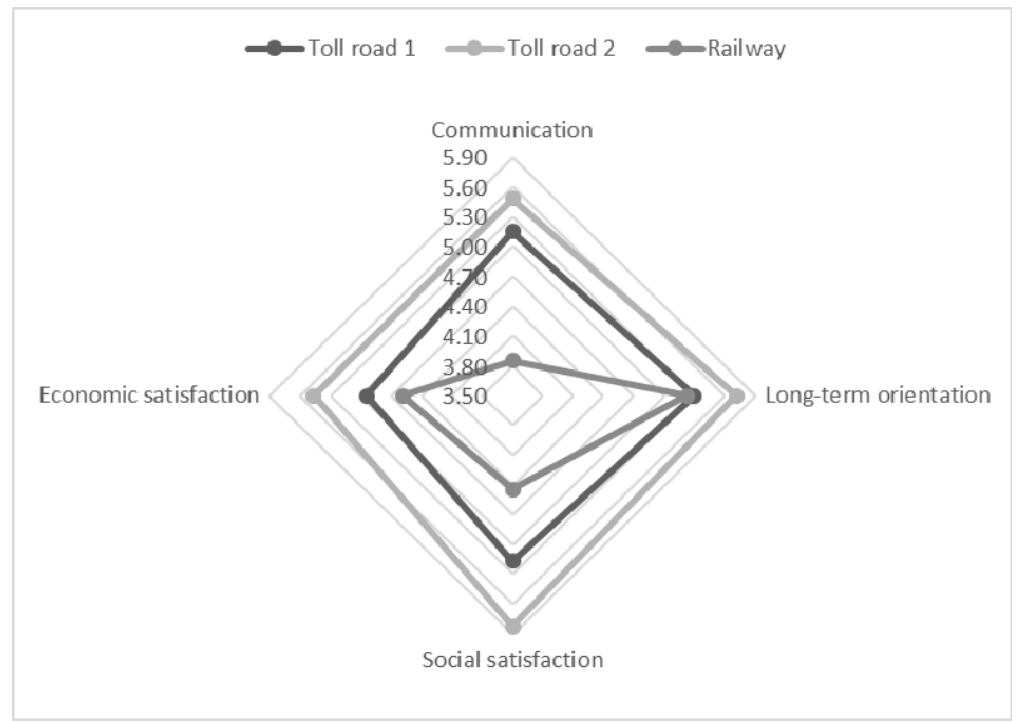

Fig. 1. Relationship quality across three different culture of the projects

The Kruskal-Wallis test (Table 1) showed that three of five dimensions of the project culture differ across three selected projects. The mean rank results (Table 2) also exhibited that the toll-road 2 project scored higher than two other projects. However, the dimensions of flexible and people-oriented did not present the same differences among three cases. Data acquired during interviews confirmed findings from the questionnaire, indicating that project participants were comfortable with uncertainty situations and respected each other. It was reported: "before commencing the project, we always conduct an initial meeting to discuss any possible conditions during the project lifecycle". In the meeting, among interviewees revealed that every project parties were willing to cordially express their doubts in providing early warning of potential problems.

The radar chart (Fig. 1) depicted that the level of relationship quality in the toll-road 2 project was better than two other projects. However, due to the small sample size of the survey, it is not possible to state that the there was a causal correlation between project cultures and the level of relationship quality, although it may have been. Therefore, semistructure interviews were conducted with key project participants to explore the manifestation of project culture and its possible linkage with relationship quality. There was an evidence that toll-road 2 had a concern regarding social interaction between project parties. It was reported: "we created a conducive circumstance that made most project parties feeling satisfy."

\section{Conclusions}

This study applied a case study method to compare the culture and relationship quality of three Indonesian transport infrastructure projects. Key project participants or 10 participants from the client, contractor, consultant, suppliers/ subcontractors were involved in the survey, and followed by semi-structured interviews. The result from the survey indicated that the project with integrative, cooperative, and goal oriented performed better 
relationship quality. Nevertheless, it is not possible to determine causality relationship between project culture and relationship quality, since the limitation of sample size in this study. A strong project culture is a key in managing social interaction between project parties that lead to promoting a harmonious relationship among project members. The high level of relationship quality between project parties will foster collaborative teamwork which in turn will contribute to achieving better project outcomes.

This research project is funded by LPDP (Indonesia Endowment Fund for Education) scholarships on behalf of the Ministry of Finance of the Republic of Indonesia.

\section{References}

1. Oxford Economic, Capital project and infrastructure spending outlook to 2025 (Price Waterhouse Coopers, London, 2017)

2. Databoks, Anggaran infrastruktur 2009-2017 terus meningkat. Available at: http://databoks.katadata.co.id/datapublish/2016/11/03/anggaran-infrastruktur-20092017-terus-meningkat (2016)

3. E.M. Kamal, R. Flanagan, J. of Eng. Design and Tech. 10, 2 (2012)

4. P.J. Mccord, D.E. Gunderson, Int. J. of Con. Education and Res. 10, 2 (2014)

5. H. Smyth, S. Pryke, I. Wiley, Collaborative relationships in construction: developing frameworks and networks (Blackwell Publishing, London, 2008)

6. P. Humphreys, J. Matthews, M. Kumaraswamy, Supply Chain Management: An Int. J. 8, 2 (2003)

7. Australian Bureau of Statistic, Industrial Disputes (Australian Bureau of Statistic, Canberra, 2016)

8. L.E. Bygballe, A.R. Swärd, A.L. Vaagaasar, Int. J. Project Man. 34, 8 (2016)

9. L.E. Bygballe, M. Jahre, A. Swärd, J. of Purchasing and Supply Man.t 16, 4 (2010)

10. X. Meng, Int. J. of Project Man. 30, 2 (2012)

11. H. Doloi, J. of Man. in Eng. 29, 3 (2013)

12. Y. Ning, F.Y.Y. Ling, J. of Construction Eng. and Man. 140, 1 (2014)

13. Y.K.F. Cheung, S. Rowlinson, Int. J. of Man. Science and Business 4, 3 (2011)

14. G.D. Wood, R.C.T. Ellis, Construction Man. and Econ. 23, 3 (2005)

15. Z. Jiang, E. Shiu, S. Henneberg, P. Naude, Psychol Mark 33, 4 (2016)

16. M. Babaeianjelodar, Understanding relationship quality in construction projects: A study of the New Zealand construction industry (Research Space, Auckland, 2015)

17. A.O. Ujene, U.E. Edike, Int. J. of Construction Man. 15, 1 (2015)

18. M.B. Jelodar, T.W. Yiu, S. Wilkinson, Int. J. of Project Man. 34, 6 (2016)

19. D.Y. Lee, P.L. Dawes, J. of Int. Marketing 13, 2 (2005)

20. C.R. Lages, C. Lages, L.F. Lages, J. of Business Res. 58, 8 (2005)

21. K. Roberts, S. Varki, R. Brodie, European J. of Marketing 37, 1/2 (2003)

22. M.J. Dorsch, S.R. Swanson, S.W. Kelley, J. of The Academy of Marketing 26, 2 (1998)

23. D. Bejou, B. Wray, T.N. Ingram, J. of Business Res. 36, 2 (1996)

24. M. Bresnen, N. Marshall, ARCOM 14th Annual Conference, University of Reading Proc. 2 (1998) 
25. C. Egbu, P. Bernard, Proc. ARCOM (2000)

26. H. Smyth, Relationship management and the management of projects (Routledge, Abingdon, 2015)

27. R.L. Conville, L.E. Rogers, The meaning of" relationship" in interpersonal communication (Greenwood Publishing Group, London, 1998)

28. X. Meng, J. of Civil Eng. and Man. 21, 7 (2015)

29. H.R. Thomas, C.J. Flynn, Practice Periodical on Struct. Des. and Con. 16, 3 (2011)

30. D. Willar, Improving quality management system implementation in Indonesian construction companies (Thesis, Queensland University of Technology, Queensland, 2012)

31. S. McCabe, Quality improvement techniques in construction: principles and methods (Routledge, Abingdon, 2014)

32. J. Nummelin, Proc. of the British University in Dubai, Joint Int. Conf. on Construction Culture Innovation and Management: Sustainable (2006)

33. J. Zuo, Project culture in the Australian construction industry: lessons for China (University of South Australia, Adelaide South Australia, 2008)

34. J. Zuo, G. Zillante, Int. Journal of Construction Man. 6, 2 (2006)

35. J. Zuo, G. Zillante, Z.-Y. Zhao, B. Xia, Facilities 32, 13/14 (2014)

36. K.S. Cameron, R. E. Quinn, Diagnosing and changing organizational culture: Based on competing values framwork. (Jossey-Bass, San Fansisco, 2006)

37. G.H. Hofstede, Culture's consequences: comparing values, behaviors, institutions, and organizations across nations (Sage Publication, California, 2001)

38. E.S. Andersen, Project Man. J. 34, 4 (2003)

39. R. Thomas, M. Marosszeky, K. Karim, S. Davis, D. McGeorge, IGLC Proc. 10 (2002)

40. A. Wiewiora, The role of organisational culture, trust and mechanisms in interproject knowledge sharing (Thesis, Queensland University of Technology, Queensland, 2011)

41. B. Egginton, Int. J. of Project Man. 14, 3 (1996)

42. M. Kumaraswamy, S. Rowlinson, M.M. Rahman, F. Phua, Strategies for triggering the required 'cultural revolution'in the construction industry (University of Reading, Berkshire, 2002)

43. G.A.P.C. Dharmayanti, The impact of organisational culture in project selection process: case of public infrastructure project in Indonesia (Queensland University of Technology, Queensland, 2013)

44. R. Fellows, A. Liu, Research methods for construction (Willey-Blackwell, Oxford, 2008)

45. U. Qoyyimah, EFL teachers' professional dilemmas with moral curriculum reform in Indonesia (Queensland University of Technology, Queensland, 2015)

46. I. Seidman, Interviewing as qualitative research: A guide for researchers in education and the social sciences (Teachers college press, New York and London, 2013)

47. A. Witzel, H. Reiter, The problem-centred interview (SAGE, London, 2012)

48. Databoks, 101 proyek jokowi untuk perlancar konektivitas. Available at: http://katadata.co.id/infografik/2016/10/22/101-proyek-jokowi-untuk-perlancarkonektivitas (2016) 